\title{
Vom Warten
}

\section{Enrico Danieli}

Es gibt das schmerzhaft-erniedrigende Warten und das verheissungsvolle; doch warten, ob wir wollen oder nicht, tun wir ein Leben lang. Sie kennen Stauräume, Stauzeiten, Staukolonnen, Staumelder - den Stau. Dabei ist nicht mehr von Wartezeiten die Rede, sondern vom Zeitverlust. Sicher bin ich mir nicht, ob das Warten automatisch ein Verlust ist. Ob wir dabei viel verlieren? Und doch gibt es sie, die Wartezonen, die einzig ein Verlust sind, nicht an Zeit, an Leben. Bekannt sind uns unsere Wartezimmer, Warteräume, dann die Wartesäle, Warteecken, die Warteschleusen, Wartegänge, nun waiting rooms oder waiting areas. Ein, ist der Raum gefüllt, äusserst unangenehmer Ort. Nichts von

\section{Sicher bin ich mir nicht, ob das Warten automatisch ein Verlust ist. Ob wir dabei viel verlieren?}

Weltgesellschaft im Kleinen! Es ist nicht nur die zu enge Nachbarschaft mit telefonierenden, essenden, quengelnden, sich streitenden, handyversessenen, leidenden, schwitzenden, stinkenden Menschen, es sind nicht nur die ausgelesenen, zerfledderten Magazine und Zeitungen, nicht die seit Jahren an den Wänden klebenden Anzeigen für Mittagstisch und Babyturnen und Demenzrunden und Spenden für das GutMensch-Sein in Afrika, mehr noch ist es die bedrohliche Stimmung, die stickige Luft, das Nichtatmen- und Nicht-bewegen-Können, das Eingeschlossensein, welches unaushaltbar ist und welches dafür verantwortlich ist, diese Orte weiträumig zu meiden.

Hinzu kommen die Demütigungen medizinischer Art, die uns hier ereilen - ganz so, als befänden wir uns schon in der Hölle. Natürlich sind später Gekommene zuerst an der Reihe, natürlich werden Einzelne begrüsst wie Freunde, während andere, kaum wahrgenommen - warten, warten. Es gehe halt noch ein Weilchen! Dann, ins schwitzende Dösen hinein, die Aufforderung, vor all den Wartenden, man stelle sich vor!, zur Bisi-Kontrolle. Ob ich denn wisse, wie es gehe. Wie hat man sich zu verhalten in einer solchen Situation? Lachen? Ich habe keine Ahnung. Hier der Becher, der gut gefüllt sein müsse, zuerst aber müsse alles ganz gut gereinigt werden, speziell ganz vorn. Natürlich telefoniert niemand mehr, niemand isst, niemand liest Zeitschriften, alle hören zu und schauen und schauen und stellen sich, so wie ich, alles vor. Die erste Portion in die Schüssel, die zweite Portion, ohne den Rand zu berühren, in den Becher usw. Es ist, wie es ist, unerträglich, und doch hat man die Situation zu erdulden. Mit dem vollen Becher wieder zurück durch das Wartezimmer zur grossen Theke.

Das Warten dort mit dem Becher in der Hand, weil Wichtigeres Vorrang hat. Wieder warten, die Kunden, früher: die Kranken, haben sich wenig verändert, mein Platz ist besetzt, ich habe mich auf einen Kinderstuhl zu setzen. Das Schliessen der Augen, damit verbunden die Hoffnung, weniger zu hören, eine trügerische Hoffnung. Später die Aufforderung zum Labor, denn man müsse mich piksen, ob ich denn keine Angst habe, es schmerze nicht, ob ich auch schon gepikst worden sei, es gebe nur einen einzigen Piks. Das alles ist mitten im Schrecken ohne Ende noch das am wenigsten Schreckliche.

Doch das Schlussbouquet folgt auf dem Fuss, denn auch noch habe man mich zu pulsen, den Blutdruck zu nehmen, und, da alles zu tief ist, sei das sehr gut - für ein langes Leben. Dass mir davor in diesem Moment graut, brauche ich nicht zu erläutern. Und nur wenige Augenblicke danach, ich habe mich wieder auf den Kinderstuhl gezwängt, werde ich erneut aufgerufen,

\section{Wie hat man sich zu verhalten in einer solchen} Situation? Lachen?

um das Gewicht zu nehmen. Die Waage befindet sich neben der offenstehenden Türe in einer Nische bei der Anmeldetheke, von allen Seiten gut einsehbar. In den Kleidern stelle ich mich auf die Waage, was Gelächter zur Folge hat. Bis aufs Hösli, werde ich ermahnt, habe ich alles auszuziehen. Es ist, im Nachhinein, die Hölle, und alle, alle schauen zu, die vom Wartezimmer, die bei der Anmeldung und die hinter der Theke. Nackt, beinahe nackt stehe ich frierend auf der Waage, die Kleider liegen in einem Haufen vor mir, es gibt keine Ablagemöglichkeiten.

Später, nach der ärztlichen Visite, werde ich gebeten, mit dem Labor einen Termin zu fixieren, denn Blut und Wasser müssten nüchtern nachkontrolliert werden. Unfreundlich verlasse ich die Praxis, ich würde mich melden, sage ich zum Abschied, und weiss, dass ich nie mehr in meinem ganzen Leben zurückkommen werde. 